\title{
Building Management System to support building renovation
}

\author{
Hang Yin
}

Department of Civil and Environmental Engineering, UCC

\section{Introduction}

Many publications have concluded that around $40 \%$ of the world's energy costs are incurred in buildings. The biggest energy users in a building are facilities which cover $40 \%$ to $60 \%$ of the total energy cost. In recent years, construction work undertaken in building renovation and rehabilitation has increased considerably. Technical renovations have always brought better building management. Modern technology has a more user friendly interface as well as giving us the successful management of building systems and associated reduced costs. In order to implement more energy efficiency in existing buildings, Building Management System (BMS) and Building Information Modelling (BIM) play important roles in the energy \& cost savings of the building's life.

This paper emphasises the use of Information and Communication Technology (ICT) to support and justify essential building renovation that will improve a building's performance and decrease annual energy costs. We will present an introduction to BMS and BIM and energy costs analysis. BIM will not only support the BMS but also can be used to analyse building performance.

\section{The usage of Building Management System in building}

A BMS is a system that not only provides automatic monitoring and control of services such as lighting, plumbing, fire services, heating, cooling and ventilation, but also supports comfort and energy efficiency. The objective of a BMS is to enhance building operational condition monitoring and control. The BMS is often an effective solution to cost conscious building management strategies and it enables employees and occupants of a facility to be more productive. Investing in a BMS can save more than $14 \%$ in annual costs measured in lost productivity, according to studies by the Atlanta-based American Society of Heating, Refrigerating and Air-Conditioning Engineers (ASHRAE). A Building Management System minimizes energy consumption and maximizes indoor comfort. A fully optimized BMS can save energy costs to the extent of $15 \%-20 \%$ as compared to a building without a BMS. 


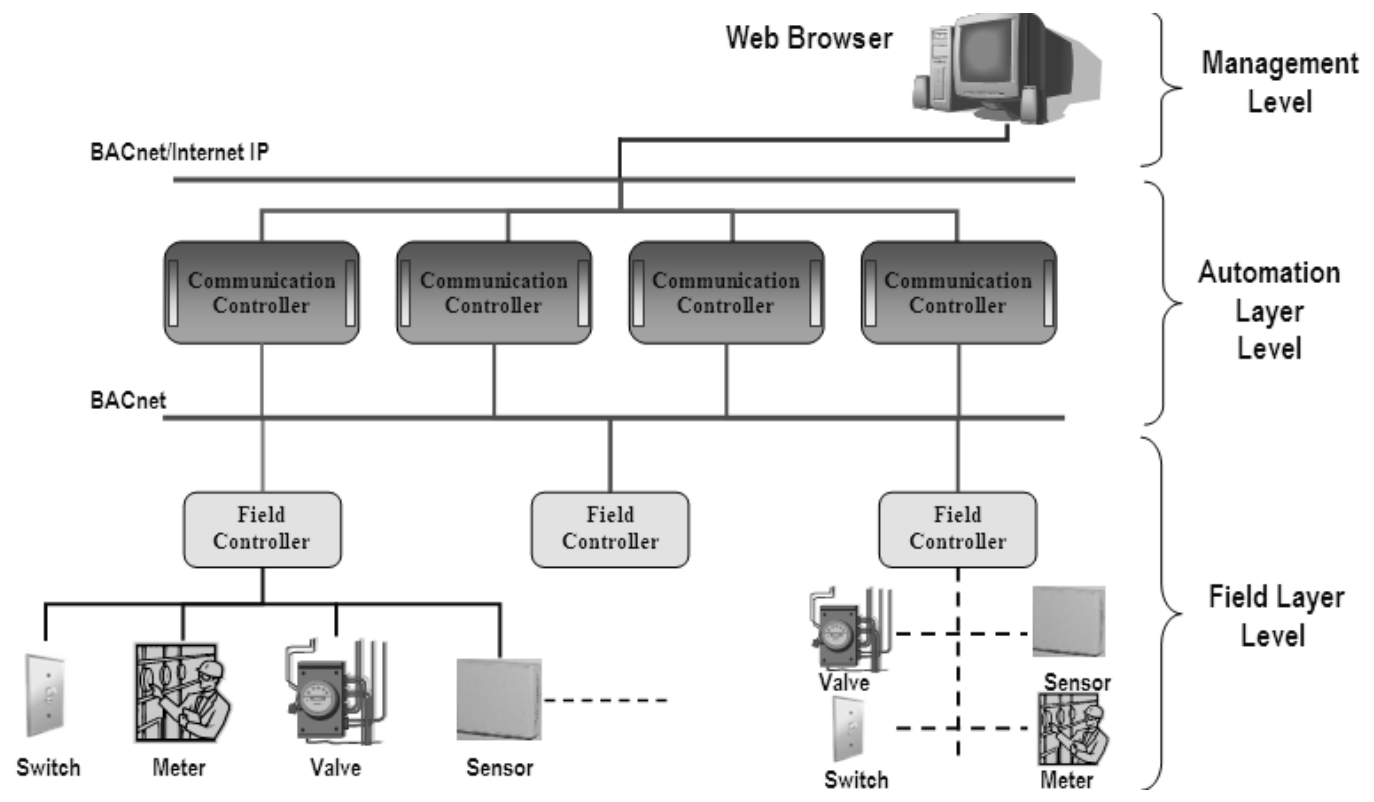

Figure 1: The basic structure of Building Management System

The primary motivation of this paper is to use a BMS to monitor a building's operation and energy performance. This system can collect real-time data (e.g. temperature, CO2 and humidity etc.) from wired and wireless sensors. Real-time data collection not only provides a clear roadmap about how a building is performing but also delivers data for evaluation \& ratification of a three dimensional (3D) model in BIM.

Generally, the BMS term covers all control elements, including hardware, controllers, any linking network and central controllers. A BMS consists of field layer level, automation layer level and management level. In field layer, filed controllers get a single or stimulus and respond from sensors, meters, switches or valves. The function of the automation layer is running and communication. When this layer gets data from filed layer, they transit them to an interface (Web Browser), which can display all information. The basic structure of a Building Management System is shown in Figure 1 as follows:

Our researchers and industry partners have successfully implemented a BMS into the Environmental Research Institute (ERI) building at University College Cork. The ERI is a 3 storey research building containing offices, meeting rooms, laboratories etc. The building's owner carries out ongoing experiments into the operation of green buildings. In the ERI building the BMS is implemented to tracking various sensors and meters. It is also used for controlling environmental conditions in the building.

A sensor network is the most basic component in a BMS and the accuracy required needs to be specified at design. Building Information Modelling (BIM) provides a big opportunity to design the sensor network and store Sensors specifications. 


\section{Building Information Modelling}

BIM is the process of generating and managing building data during the life cycle of the building. Typically it uses 3D, real-time, dynamic building modelling software to increase productivity in building design and construction. It is a mature digital framework that models building components and their relationships.

In this paper, we will present two aspects of BIM application. Firstly, the BIM is always used to design sensors network and store BMS data. Secondly, it is used to make a building performance analysis through energy simulation modelling which can supply assistance to renovate old buildings.

\section{Define sensors requirements}

BIM is an integrated database of coordinated information to which many participants in the design process contribute. It is the most appropriate medium for storing building and performance data to define sensors requirements during the BMS process. Building geometry, HVAC (Heating, Ventilating, and Air Conditioning) systems and lighting system must be instantiated in the BIM. A performance hierarchy that defines the sensor requirements in a building must also be instantiated and are in turn passed to the sensor network design tool. Sensor specifications are stored in the BIM after completion of the sensors network design (See Figure 2).

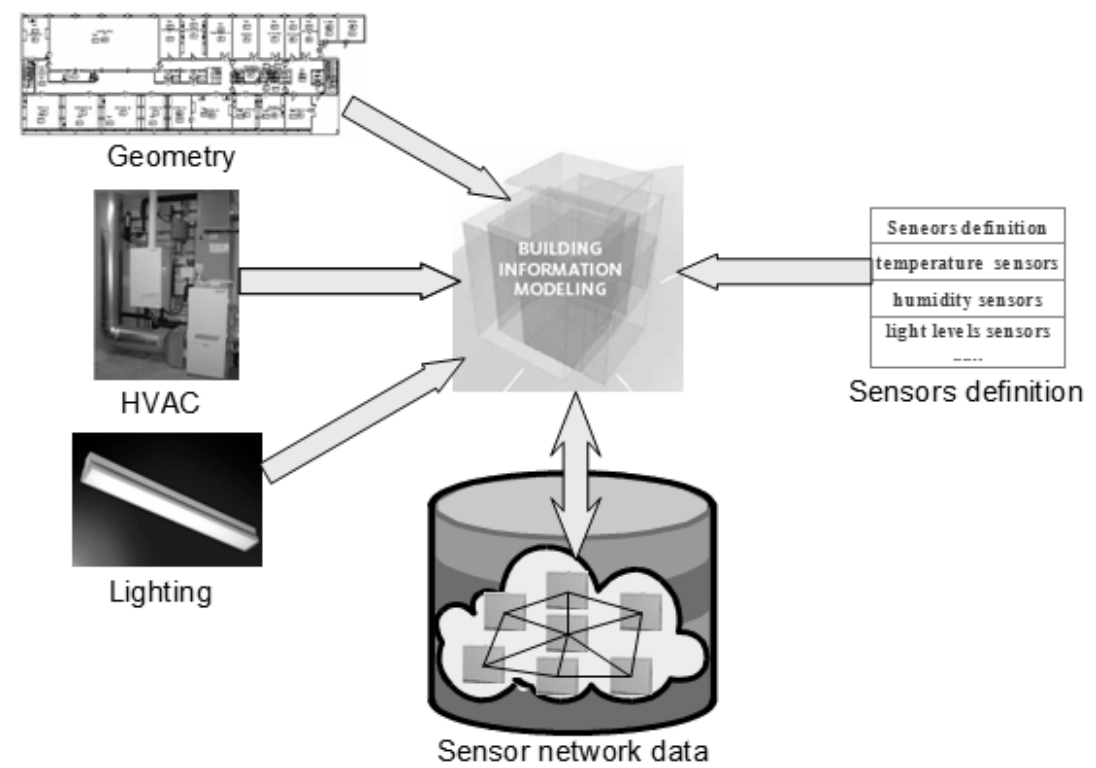

Figure 2: The role of BIM 


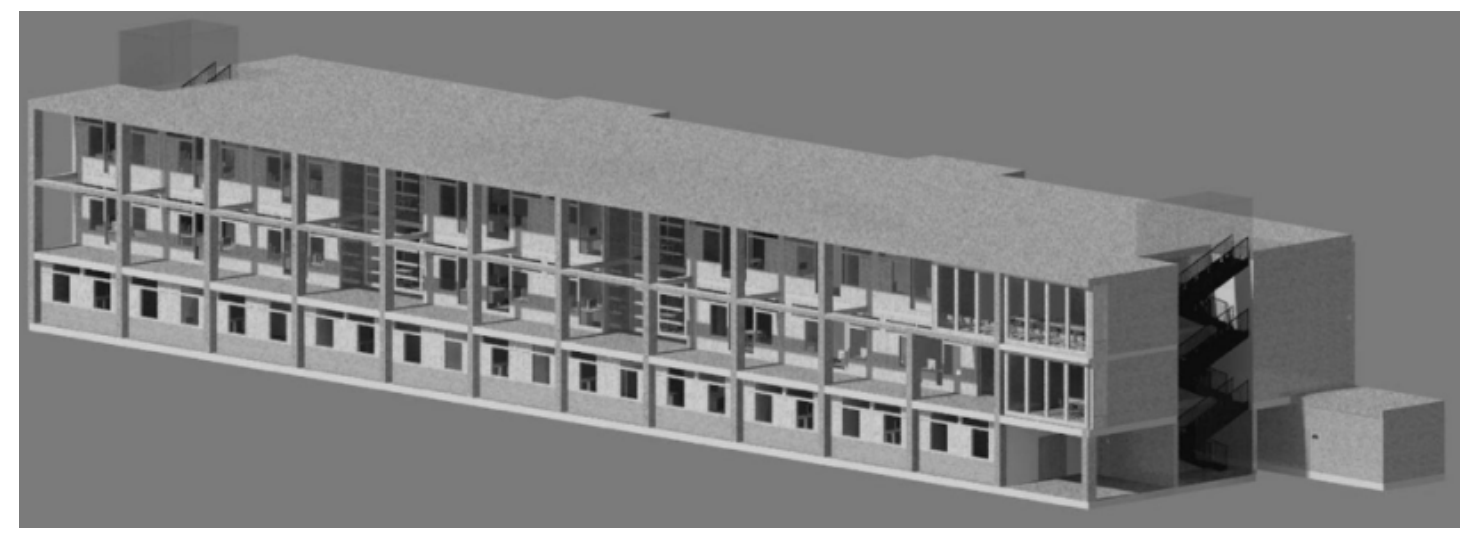

The simulated Loads Report shows the actual total heating load as 218.7KW for the ERI building. Total energy usage $=$ total heating load $\times$ operation hours / boiler efficiency. Accordingly, the total energy usage per year is $572,994 \mathrm{kWhrs}\left(175 \mathrm{kWhrs} / \mathrm{m}^{2} / \mathrm{yr}\right)$

Figure 3: A 3D model of the ERI building

\section{Energy simulation model}

In order to successfully improve the building's performance and reduce costs, a sustainable approach to analysis can be developed. BIM offers key information about the building that can be used to analyse its performance. The geometry, HVAC system and lighting system of the virtual building are stored in the BIM as 3D models. The simulation model greatly contributes to the understanding of energy utilization profiles in buildings and the building systems' impact on energy usage. Energy simulation models act as a data source for simulated performance metric generation. The BMS can be used to continuously monitor the building and provide data for calibration of the simulation model.

Autodesk Revit Architecture and Revit MEP is one software package to create detailed model. The geometric representation of an existing building can be created in Revit Architecture and the HVAC and light systems can be created in Revit MEP. An additional piece of software (limited IES VE Integrated Environmental Solutions) is embedded within a Revit MEP plug-in to simulate heating and cooling loads on existing model. We can compare actual energy consumption provided by the BMS with energy simulation, allowing a better evaluation \& verification of the 3D model in BIM.

We have developed a simulation model of the ERI building. Figure 3 presents the 3D model for energy simulation. After simulation, a report is produced giving details about the heating and cooling loads for each room.

The simulated Loads Report shows the actual total heating load as 218.7KW for the ERI building. Total energy usage $=$ total heating load $\times$ operation hours $/$ boiler efficiency. Accordingly, the total energy usage per year is $572,994 \mathrm{kWhrs}\left(175 \mathrm{kWhrs} / \mathrm{m}^{2} / \mathrm{yr}\right)$ At the same time, we collected energy usage data from the BMS and then calculated that the figure of energy consumption including gas and electricity was $182 \mathrm{kWhrs} / \mathrm{m}^{2} / \mathrm{yr}$. It is clear that results provided by simulation and BMS only a 3 percent difference. 


\section{Energy Cost Analysis}

BMS control building system operations automatically and in the most efficient way possible in order to improve energy efficiency and reduce fuel use and costs. The total energy usage and annual cost of the ERI building from heating and electricity are summarised in Figure 4 below. The electricity of the ERI is from wind farm which is connected to the electric power transmission network. Therefore, the site is supplied by renewable power. Finally, Figure 4 also gives some benchmarking criteria provided by TM 22. According to the cost type, the TM 22 benchmarking criteria is $15.6 £ / \mathrm{m}^{2}$ and $2.4 \mathrm{f} / \mathrm{m}^{2}$ for Good Practice of electric annual cost and fossil fuel annual cost separately.

A comparison of the above results with benchmarks taken from TM 22 standards is presented in graph below:

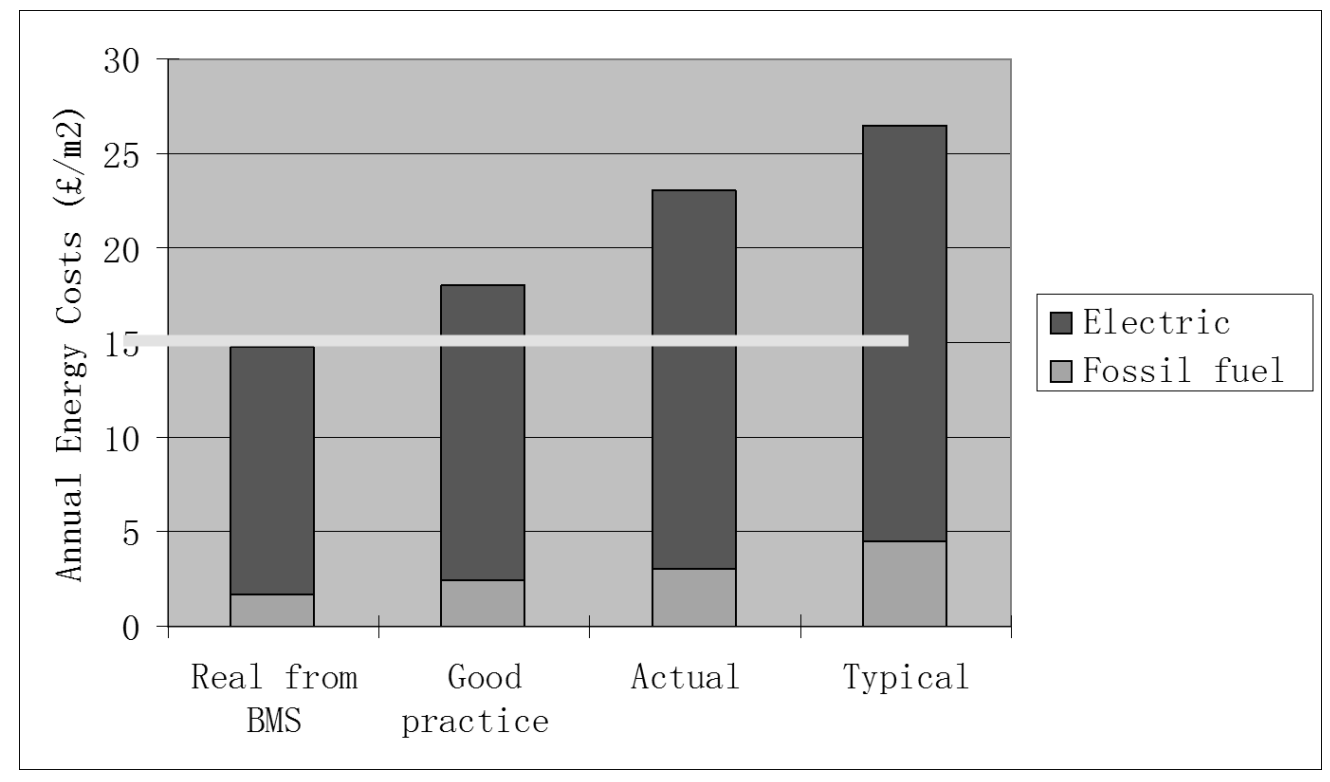

Figure 4: Cost analysis

\section{Conclusions}

There are various smart technologies available nowadays that can help reduce energy consumption and cost of existing buildings. Occupants can install a BMS to automate building functions such as lighting and HVAC system and to allow the facility managers to prevent customer complaints and moreover can reduce the cost of operating the building by $15 \%-20 \%$. According to the Energy Cost Analysis illustrates that the total cost per annum is $14.8 \mathrm{E} / \mathrm{m}^{2}$ which is lower than annual costs for good practice according to the benchmark therefore indicating the excellent influence of BMS.

The BMS gives not only historical data but also real time data. The former is important 
to owners and facility managers as it gives information relating to trends such as the maintenance required on a piece of machinery or the energy usage of users such as tenants and occupiers. Historical data is also important as it allows costs to be calculated and as accurately budgeted as possible. The latter case, real time data, allows facility managers and owners to make decisions as occasions occur. This is particularly important when considering user comfort. The BIM allows for the easy management of sensors that provide the required data on which decisions are made. It also gives a graphical representation that can be easily understood and utilised by the facility managers and owners. This has been adequately demonstrated in the case of UCC's ERI building.

BMSs have already been implemented in the world, such as Federal Ministry of Finance Building in Berlin, Beijing Bank Headquarters Office Building, Yang and Yamazaki Environment and Energy Building (Y2E2), etc. However, other smart technologies have been to develop for huge energy-saving and carbon-neutral building.

Thanks to my supervisor Karsten Menzel and my colleagues Zixaing Cong, Michal Otreba and Luke Allan. 